\title{
Novel Activated Carbon Monoliths for Methane Adsorption Obtained from Coffee Husks
}

\author{
Liliana Giraldo ${ }^{1}$, Juan Carlos Moreno-Piraján ${ }^{2 *}$ \\ ${ }^{1}$ Departamento de Química, Facultad de Ciencias, Universidad Nacional de Colombia, Bogotá. Colombia; ${ }^{2}$ Grupo de Investigación \\ en Sólidos Porosos y Calorimetría, Universidad de los Andes, Bogotá, Colombia. \\ Email: jumoreno@uniandes.edu.co
}

Received March $6^{\text {th }}, 2011$; revised March $16^{\text {th }}, 2011$; accepted March $24^{\text {th }}, 2011$.

\begin{abstract}
Methane adsorption by different forms of activated carbon obtained from coffee husks, including monolith honeycomb and disc types, was studied by activation with zinc salts and potassium hydroxide at $298.15 \mathrm{~K}$ and $303.15 \mathrm{~K}$ and pressures up to $30.00 \mathrm{~atm}$ in a volumetric adsorption apparatus. We observed increased methane adsorption capacity on a mass basis in the different activated carbon monoliths with increasing surface area, total pore volume and micropore volume, with the honeycomb type displaying the highest methane absorption capacity. The maximum volumetric methane uptake by the synthesised carbon monoliths was observed to be $130 \mathrm{~V} / \mathrm{V}$ at $298.15 \mathrm{~K}$ and $30.00 \mathrm{~atm}$ for honeycomb monoliths synthesised with zinc chloride $\left(\mathrm{ZnCl}_{2}\right)$ and Polyvinyl alcohol (PVA) as the binder. Adsorption calorimetry results were used to describe the interaction between guest molecules and the adsorbent at low surface coverage and the energetic heterogeneous surface nature of the adsorbent.
\end{abstract}

Keywords: Coffee Husk, Activated Carbon, Isotherm Adsorption, Carbon Monolith, Methane Adsorption, Isosteric Heat of Adsorption, SEM

\section{Introduction}

The global crisis over the coming shortage of fossil fuels is increasing, while the environmental effects of continued fossil fuel use are already being felt in the form of the greenhouse effect and global climate change. Because of this environmental crisis, researchers have proposed several interesting solutions to avoid the massive use of fossil fuels, which will hopefully result in a cleaner planet. One of these proposals is to develop materials that enable storage and subsequent release of less harmful fuels, such as methane. In fact, published research on this topic has been increasing over the past few years, and several ingenious developments have emerged. Various solids with very high porosity have been developed, and, through materials engineering, highly specific structural designs have been created in an attempt to optimise substrates for methane storage. Activated carbon is widely used in adsorption separation processes, because of its attractive adsorption properties [1-5]. As such, large amounts of data have been published concerning the adsorption isotherms of pure and multicomponent gases on activated carbon [6-10]. Natural gas fu-els, which satisfy both environmental and economical concerns, are one of the most desired fuels in the energy field, especially in comparison with liquid fossil fuels such as gasoline and diesel. Natural gas is abundant and the cleanest burning alternative transportation fuel available.

After testing at the laboratory level, pilot natural gas vehicles (NGVs) have been evaluated, with some amazing results. In fact, investigators reported that NGVs have been certified to meet the most demanding environmental emission standards. Although methane is more convenient than liquid fuel, due to its low energy density at standard temperature and pressure (STP) conditions, the storage of large amounts of methane in a given volume is very difficult. Thus, methane storage has become an important challenge for researchers in this field [11]. In addition, the development of natural gas storage and transportation technologies will be very important for the future. Although several authors have proposed that well- known conventional methods, such as liquefied natural gas (LNG) and compressed natural gas $(\mathrm{CNG})$, may be the solution for methane storage purposes, these methods are associated with both safety and cost effectiveness problems [12-14]. For example, 
even though storing high density methane in LNG vehicles is possible at cryogenic temperatures, the specialised container design and refuelling procedure required are undesirable for vehicular fuel applications. Similarly, $\mathrm{CNG}$, with its low energy density compared to gasoline, requires multi-stage compression that increases its cost and necessitates the use of a relatively large fuel tank [15]. Compared to CNG and LNG, adsorbed natural gas (ANG) is one of the best alternatives for natural gas storage and for the inevitable technologies for storing natural gas at $3.5 \mathrm{MPa}$ at room temperature [15-17]. Indeed, because of its low capital and low operating costs versus $\mathrm{CNG}$, the $\mathrm{ANG}$ process is being considered for on-board technology in NGVs [18]. One of the biggest obstacles to the implementation of ANG technology is the development and evaluation of adsorbents [16]. While the majority of carbon adsorbents are granular, powder, or fibres, an adsorbent with a large volume of pores and a high surface area is required for maximal adsorption on a mass basis [19]. Activated carbon exhibits the largest adsorption capacity and highest ANG energy: highly microporous carbons are the most promising adsorbents for natural gas storage.

Evaluation of pure-gas adsorption isotherms is an easy and straightforward method for experimentally measureing adsorption levels with high accuracy. Natural gas is considered to be one of the most promising alternative fuels, because of its abundance, low cost and minimal emissions. However, natural gas requires a special storage system [1], because of its low volumetric energy density [12,13,20-24], and the adsorbed natural gas (ANG) storage represents a feasible solution to this technological challenge [22-30]. ANG methanol is a method where both the adsorption and compression processes are carried out simultaneously, in order to store natural gas under convenient temperatures and pressures compared to conventional methods $[10,23,28-39]$. Activated carbon (AC) has been extensively used in the ANG process as an adsorbent, because of its highly microporous surface [22-24,31,37]. Activated carbon has been prepared from various precursors, including different biomasses [37]. Unfortunately, highly porous activated carbons display relatively lower natural gas adsorption capacities on a volume basis, because of their lower packing density $[7,9,13,30]$. Thus, monolithic forms of activated carbon have been employed in ANG storage systems, to achieve improved storage capacity [16,38-40]. These monolithic forms of activated carbon display increased packing density through a reduction of excess void volume [40], and offer increased compactness and easy handling. Carbon monoliths are normally made by compressing either activated carbon [22], or a mixture of activated carbon and a binder $[3,10,40]$. In the present study, we investigated the methane storage capacities of two forms of activated carbon, a powder and a monolith (honeycomb and disc), obtained by chemical activation of waste coffee husks: an abundant waste product. Evaluations were conducted using published procedures reported in the literature [22-24,37,39], to enable comparison of our results with previously published results. Carbon monoliths were prepared using binders and an impregnating agent $[5,41,42]$. After careful screening, the activated carbon monoliths were selected for methane storage analyses. The physical properties of the carbon monolith samples were characterized by $\mathrm{N}_{2}(77 \mathrm{~K})$ adsorption isotherms [43,44]. Heats of adsorption for pure-component adsorption may be obtained experimentally from adsorption calorimetry [4547]. The methane adsorption capacities of the carbon monoliths were assessed using a volumetric adsorption method at two constant temperatures (298.150 and $303.150 \mathrm{~K}$ ) and a pressure up to $35.00 \mathrm{~atm}$. In addition to methane adsorption behaviour on the carbon monoliths, the interaction between the adsorbent and adsorbate at low surface loading, and the heat evaluation during adsorption were examined using Clausius-Clapeyron equations [19,48-51].

\section{Experimental}

\subsection{Preparation of the Carbon Monoliths}

Husks from Colombian coffee beans were impregnated with an aqueous solution of phosphoric acid following a variant of the incipient wetness method, as described elsewhere [51]. Briefly, aqueous solution $(1.4 \mathrm{ml} / \mathrm{g}$ coffee bean husks) was added drop wise (while stirring the solid to facilitate homogeneous absorption of the liquid) to produce swelling, resulting in incipient wetness. $\mathrm{H}_{3} \mathrm{PO}_{4}$ (J. T. Baker (Phillipsburg, USA) was used at a concentration of $150 \% \mathrm{wt} \%$ [51,52] in the aqueous solution, defined as follows: $\mathrm{g} \mathrm{H}_{3} \mathrm{PO}_{4}$ per g coffee bean husks) $\times 100$. After impregnation, samples were dried for $4 \mathrm{~h}$ at $383 \mathrm{~K}$ in air. Thermal treatments were carried out in a vertical tubular reactor made of quartz, using $10 \mathrm{~g}$ of impregnated and dried material in all cases. All treatments were performed at a constant heating rate of 283 $\mathrm{K} / \mathrm{min}$ with an argon $(99.999 \%$ pure) flow of $50 \mathrm{STP}$ $\mathrm{cm}^{3} / \mathrm{min}$, which was maintained during both heating and cooling. An activation temperature of $723 \mathrm{~K}$ and a soaking time of $1 \mathrm{~h}$ was used. After cooling the solid pyrolysis residue to room temperature, samples were washed with milli-Q distilled water until the conductivity of the washing liquids was reduced to $<5 \mu \mathrm{S} / \mathrm{cm}$ (as measured by a $\mathrm{pH} /$ conductivity meter, Mettler Toledo, model MPC227). Resulting activated carbon samples (ACs) were dried at $383 \mathrm{~K}$ for $12 \mathrm{~h}$ in a vacuum furnace. This 
sample is marked in this work as AC-RC.

The activated carbon monolith samples (MHZ-RC: Monolith honeycomb activated with zinc chloride; MHKRC: Monolith honeycomb activated with potassium hydroxide, MDZ-RC: Monolith type disc activated with zinc chloride; and MDK-RC: Monolith type disc activated with potassium hydroxide) were synthesised under the different conditions shown in Table 1. The monoliths were prepared by pressing at 0.02 atm at a temperature of $423.15 \mathrm{~K}$. The carbon monolith samples were made from activated carbon samples obtaining from coffee husks using $\mathrm{ZnCl}_{2}$ and $\mathrm{KOH}$ as chemical activators. In final form, all four monoliths were $5 \mathrm{~mm}$ thick, with a diameter of $12 \mathrm{~mm}$.

\subsection{Adsorption Measurements}

The surface structural characteristics of the carbon monoliths were determined from $\mathrm{N}_{2}(77 \mathrm{~K})$ adsorption isotherm results (AUTOSORB 3B Quantachrome, Miami, FL, US). The apparent surface area $\left(S_{\mathrm{BET}}\right)$ of each carbon monolith was calculated by analysing $\mathrm{N}_{2}$ adsorption data according to Brunauer-Emmett-Teller (BET) theory (relative pressure range: 0.01 - 0.05) [40]. Micropore volumes $\left(V_{o}\right)$ were obtained from the Dubinin-Raduskevich equation, and total pore volumes $\left(V_{T}\right)$ were evaluated from nitrogen adsorption data obtained at a relative pressure of 0.99 using the Gurvistsch rule. The mesopore volume $\left(V_{\text {mes }}\right)$ was determined using the Barrett-JoinerHalenda (BJH) equation. Once the BET surface area $\left(S_{\mathrm{BET}}\right)$ and total pore volume $\left(V_{T}\right)$ were determined, the average pore width was calculated using the following expression: $\left(4 V_{T} / S_{\mathrm{BET}}\right)$ [40]. Resulting packing densities are also listed in Table 1. Dry materials were outgassed at $473 \mathrm{~K}$ overnight: however, to avoid water evaporation, wetted materials were not subjected to this treatment. A thermostatic device was used to maintain the temperature within a tolerance of $2 \pm 0.1 \mathrm{~K}$. Porosity development and void volume were analysed using a field emission JEOL JSM 6510 scanning electron microscope (SEM) (Japan). Scanning electron microscope images of the two types of adsorbents (activated carbon honeycomb and disc) are shown in Figures 1(a) and 1(b), respectively. The channels of honeycombs are regular with side lengths between 453 and $532 \mu \mathrm{m}$, while the channel walls have a thickness between 367 and $387 \mu \mathrm{m}$; for monoliths in the form disc a diameter of $10 \mathrm{~mm} \times 5 \mathrm{~mm}$ was obtained. High-pressure methane adsorption studies were conducted in a volumetric adsorption apparatus at two temperatures $(298.150$ and $303.150 \mathrm{~K})$ and at pressures up to $35.00 \mathrm{~atm}$. The experimental procedure and the volumetric apparatus have been previously described $[4,5]$.

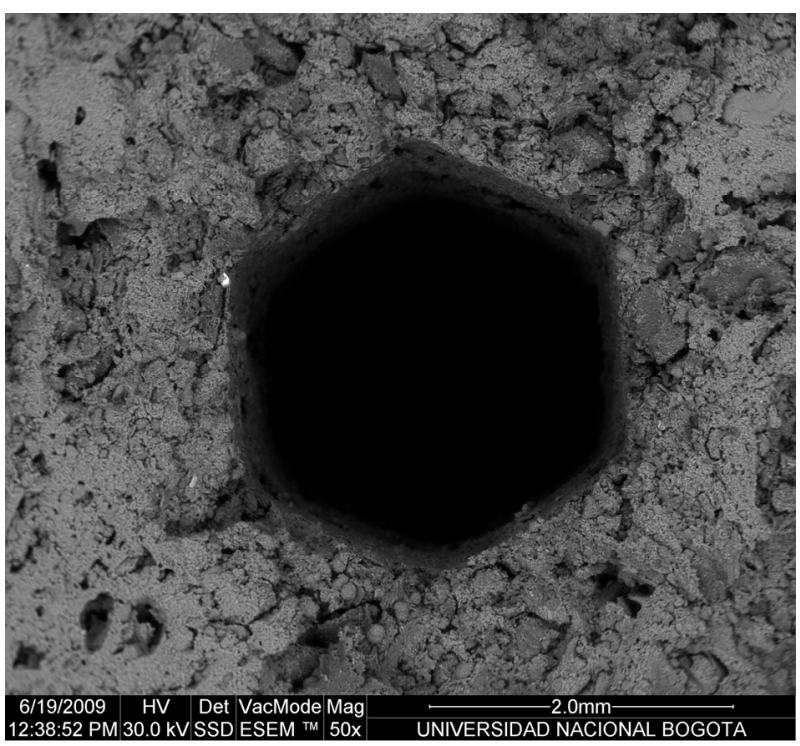

(a)

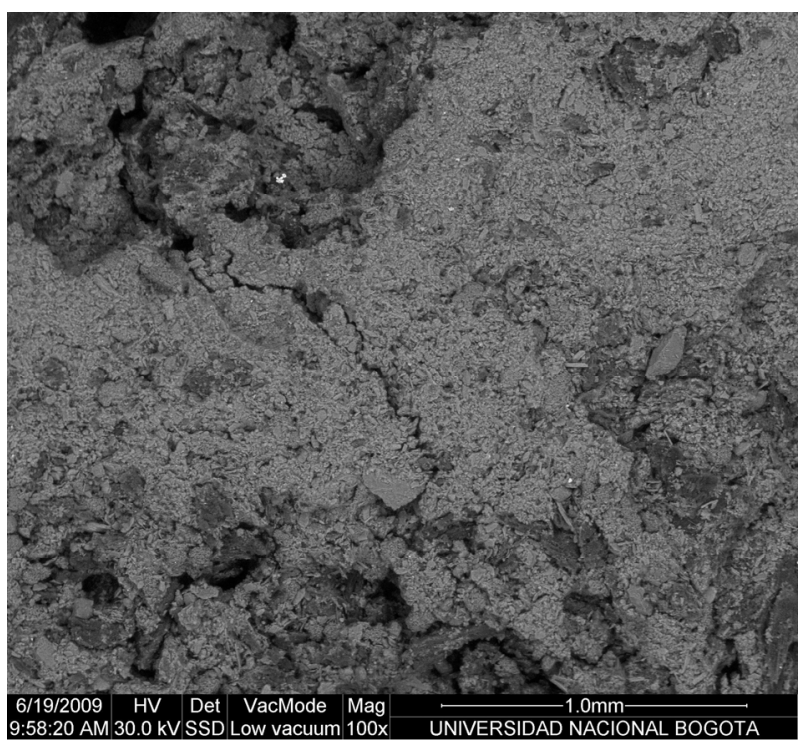

(b)

Figure 1. (a) Scanning electron microscope image of an activated carbon honeycomb monolith; (b) Scanning electron microscope image of an activated carbon disc.

The experimental apparatus used for methane adsorption at high pressure is shown in Figure 2. Initially, a high vacuum was created in the experimental device, including the cell-sample container (parts 6, 7 and 9 in Figure 2). This vacuum was achieved using a system of pumps (primary and secondary pumps, part 6) overnight. A residual pressure of $1.40 \times 10^{-7} \mathrm{~Pa}$ was observed in the system after the activated carbon monoliths were backed out and evacuated for the adsorption experiment. Afterwards, the $\mathrm{CH}_{4}$ valve was opened and methane was injected in small quantities into the introduction compart- 
Table 1. Textural properties of activated carbon type honeycomb monoliths.

\begin{tabular}{|c|c|c|c|c|c|c|c|c|}
\hline & $\mathbf{N}_{2}$ a $77 \mathrm{~K}$ & & & & & & & \\
\hline Sample & $\mathrm{S}_{\mathrm{BET}} \mathbf{m}^{2} / \mathrm{g}$ & $V_{0} \mathbf{c m}^{3} / g$ & $\begin{array}{l}V_{\text {meso }} \\
\mathbf{c m}^{3} / g\end{array}$ & $V_{t} \mathrm{~cm}^{3} / \mathrm{g}$ & $\mathbf{V}_{0} / \mathbf{V}_{\mathbf{t}}$ & $\begin{array}{c}\text { Average pore } \\
\text { width }(A P W)(\AA)\end{array}$ & $\begin{array}{c}\text { Cell packing } \\
\text { density }\left(\mathrm{g} / \mathrm{cm}^{3}\right)\end{array}$ & $\begin{array}{c}\text { Storage capacity } \\
\text { (V/V) }\end{array}$ \\
\hline MHZ-RC & 1326 & 0.84 & 0.02 & 0.86 & 0.98 & 22.6 & 0.598 & 130 \\
\hline MHK-RC & 1187 & 0.80 & 0.01 & 0.83 & 0.96 & 31.3 & 0.561 & 125 \\
\hline MDZ-RC & 1059 & 0.76 & 0.02 & 0.79 & 0.96 & 30.4 & 0.576 & 118 \\
\hline MDK-RC & 1000 & 0.72 & 0.03 & 0.77 & 0.93 & 29.6 & 0.551 & 104 \\
\hline AC-CR & 890 & 0.59 & 0.01 & 0.64 & 0.92 & 19.8 & 0.349 & 98 \\
\hline
\end{tabular}

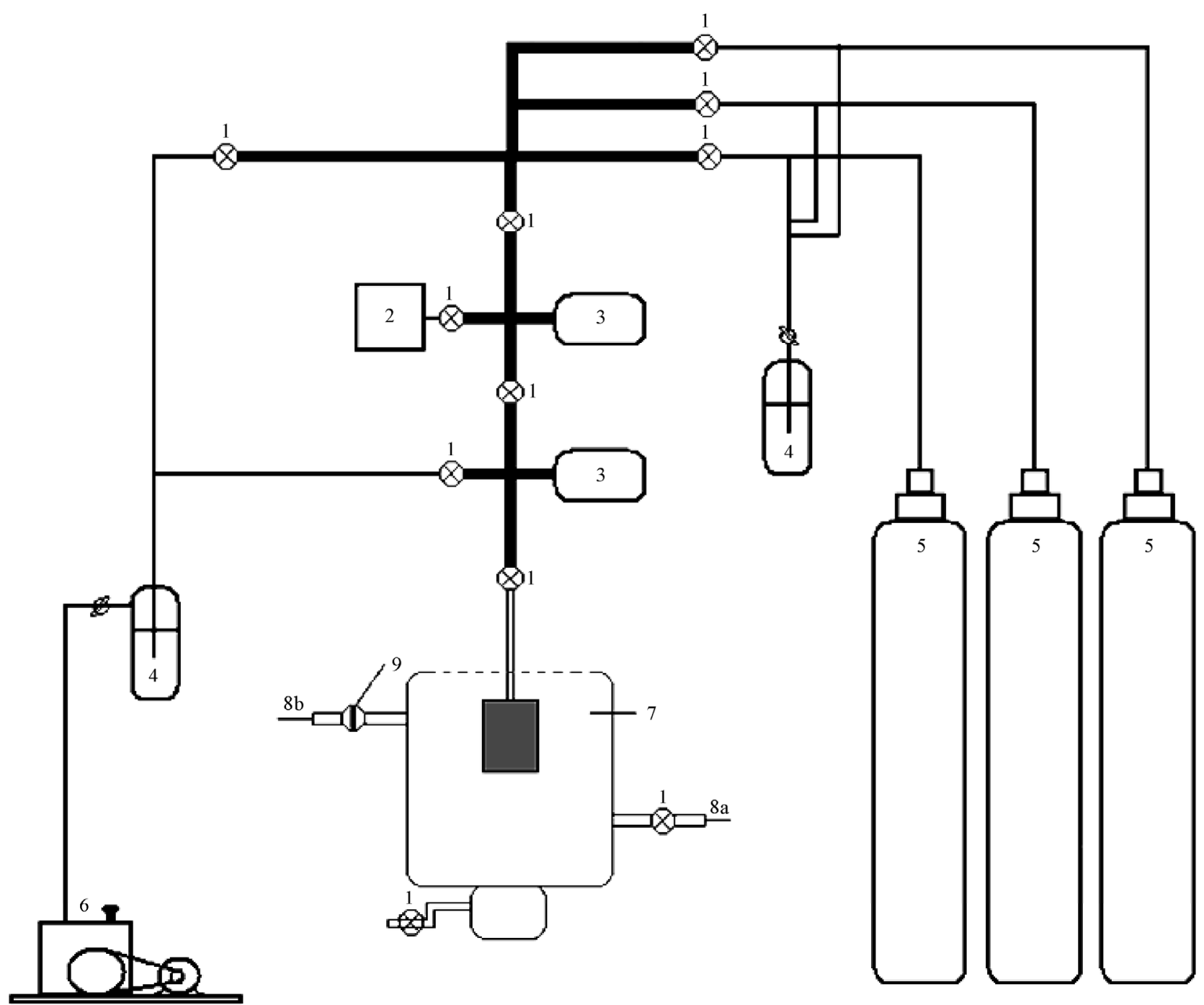

Figure 2. Experimental set-up of the equipment used to obtain high pressure isotherms, 1. Gauge, 2. pressure transducer, 3. reservoir gas, 4. cold trap, 5. gas, 6 . vacuum pump, 7. cell container, 8. valves, 9 . micrometric valve.

ment (parts 1, 2, 3 and 4 in Figure 2). The pressure value was monitored using pressure gauges (gauge 1: range from 0 to $121.31 \mathrm{~Pa}$ and gauge 2: range from 1 to 35.45
$\mathrm{kPa}$, part 3 in Figure 2). Following this step, the valve separating the introduction compartment from the cellsample container was opened and the pressure value was 
read once equilibrium was established.

\section{Results and Discussion}

\subsection{Evaluation of the Methane Storage Capacity of Activated Carbon Honeycomb Monoliths}

Characterizations data obtained from $\mathrm{N}_{2}$ adsorption/desorption isotherms are presented in Table 2, and the corresponding adsorption isotherms are shown in Figure 3. Isotherms were defined as type I, according to the International Union of Pure and Applied Chemistry (IUPAC) classification of adsorption isotherms: where type I isotherms display rapidly increasing low pressure which plateaus to a constant value of relatively high pressure. Obtained isotherms are consistent with the microporous solids in all cases.

The Brunauer-Emmett-Teller (BET) surface area of the carbon monoliths increased from $890 \mathrm{~m}^{2} / \mathrm{g}$ (for activated carbon obtained from coffee husks, AC-RC) to $1326 \mathrm{~m}^{2} / \mathrm{g}$ (honeycomb monoliths treated with zinc chloride, MHZ-RC) under the activation conditions used (impregnation chemical agent and chemical activation). The micropore volume of the carbon monoliths also increased from $0.59 \mathrm{~cm}^{3} / \mathrm{g}$ (AC-RC) to $0.89 \mathrm{~cm}^{3} / \mathrm{g}$ (MHZ$\mathrm{RC})$. Chemical activation to obtain the honeycomb type monoliths, using $\mathrm{ZnCl}_{2}$ (MHZ-RC) or $\mathrm{KOH}$ (MHK-RC) and PVA as a binder, resulted in increased surface area, micropore volume and total volume (see Table 2). Disctype monoliths, obtained by chemical activation using $\mathrm{KOH}$ with PVA as the binder, developed a smaller surface area and reduced micropore and total volumes. The effect of $\mathrm{ZnCl}_{2}$ treatment was observed in MHZ-RC and
MDZ-RC monoliths. $\mathrm{ZnCl}_{2}$ treatment enabled generation of a monolith with a surface area and pore volume of the same order of magnitude as the original activated carbon, AC-RC. Similarly, monoliths MDK-RC and MDK-CR developed surface areas and pore volumes of the same order of magnitude as AC-CR.

These results are likely due to chemical activation with $\mathrm{ZnCl}_{2}$, which has been reported to produce a larger number of pores during the activation process, as well as a greater surface area and micropore volume [5]. Activation with $\mathrm{KOH}$ also promoted development of the process surface area and porosity, but to a lesser degree. This is shown in Table 2, which illustrates the difference between the honeycomb and disc forms. Specifically, the geometric effect of the channels present in the honeycomb monoliths appear to allow for greater diffusion of gases (and therefore adsorption) than the disc-shaped monoliths.

The main goal of the present work was to obtain monoliths from coffee husks with good microporosity, which is a desirable characteristic for methane storage of methane. With these aims in mind, the CHZ-RC and MHZ-RC monoliths obtained using $\mathrm{ZnCl}_{2}$ and $\mathrm{KOH}$, respectively, were the most effective monoliths tested. Methane adsorption studies were performed at a pressure of $35.45 \mathrm{kPa}$ and at two different temperatures $(298.150$ $\mathrm{K}$ and $303.150 \mathrm{~K}$ ), and methane adsorption results are shown in Figures $\mathbf{4}$ and 5. Figure 5 shows the methane adsorption capacity by mass of MHZ-RC at $298.15 \mathrm{~K}$ and $303.15 \mathrm{~K}$ and $35.45 \mathrm{kPa}$. It can be seen that the amount of methane adsorption by MHZ-RC was signify-

Table 2. Characteristics of synthesised monoliths from coffee husks.

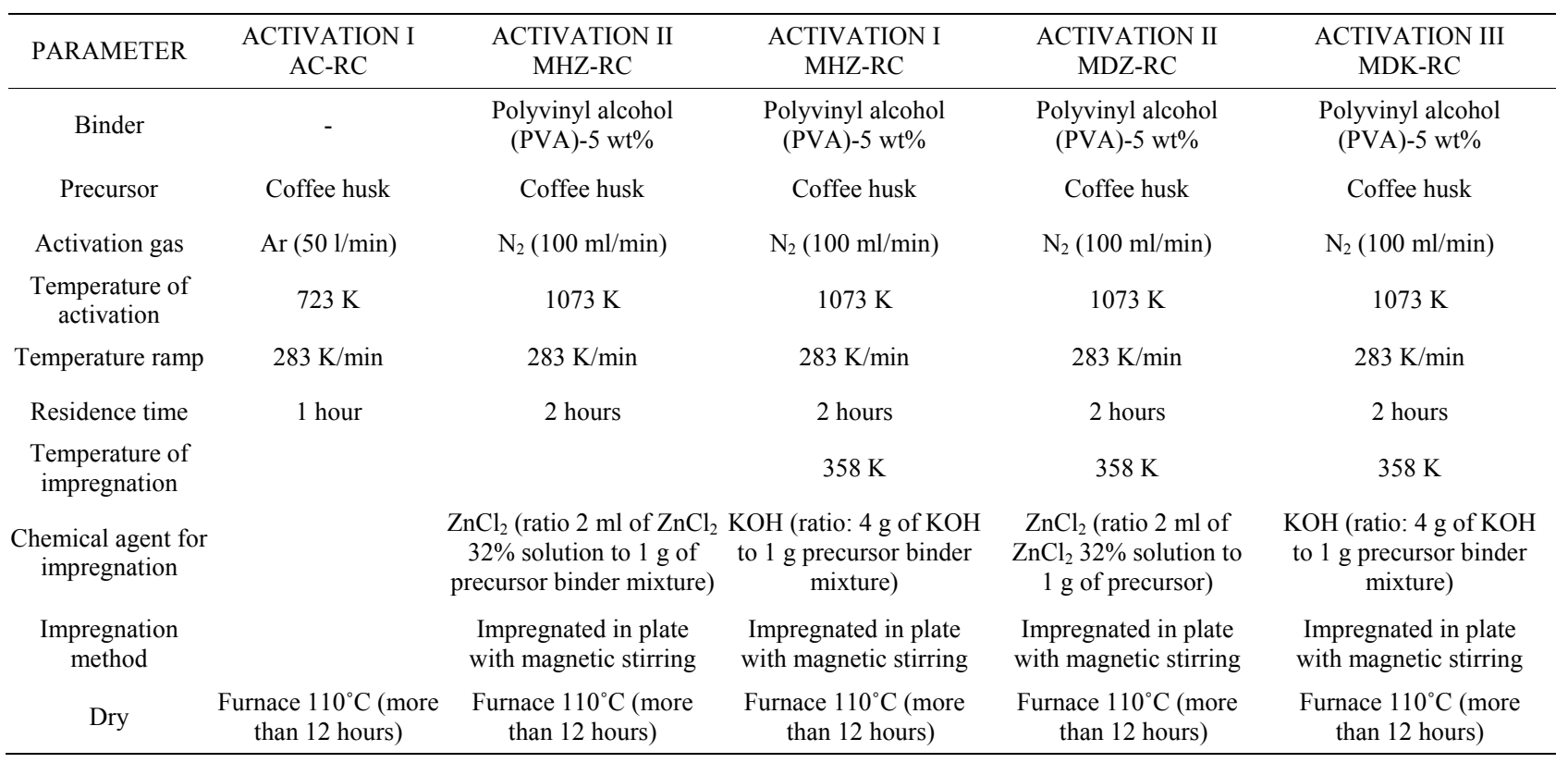




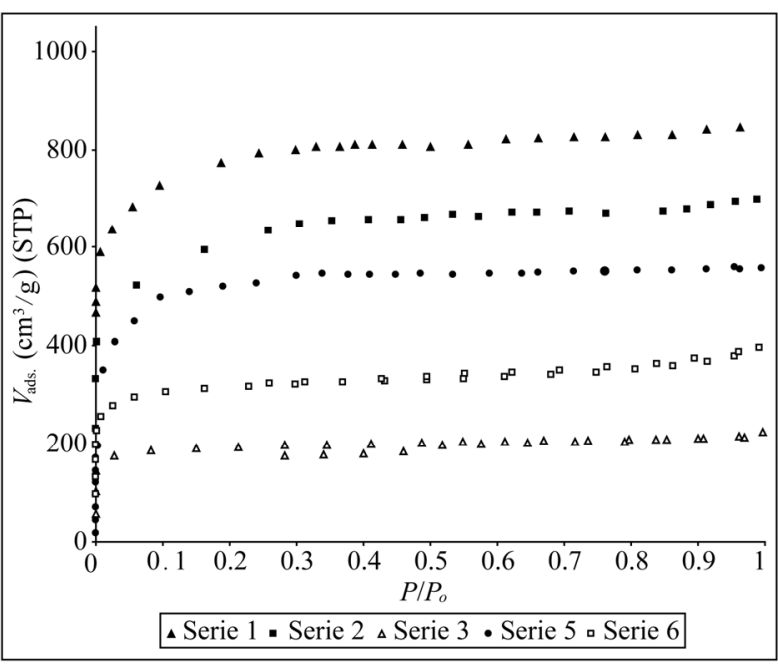

Figure 3. Adsorption isotherms of activated carbon honeycomb monolith.

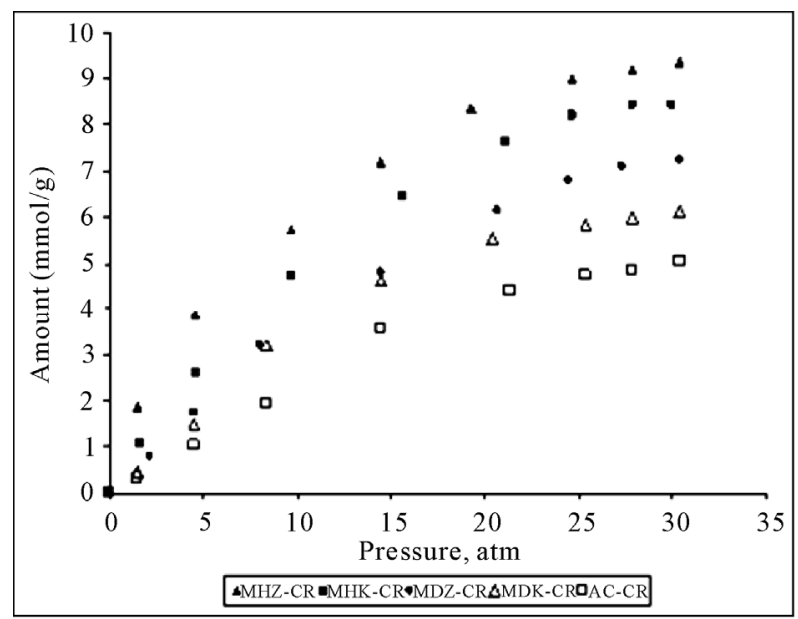

Figure 4. Methane adsorption capacity (by mass) of activated carbon monoliths at $298.15 \mathrm{~K}$ and $30.00 \mathrm{~atm}$.

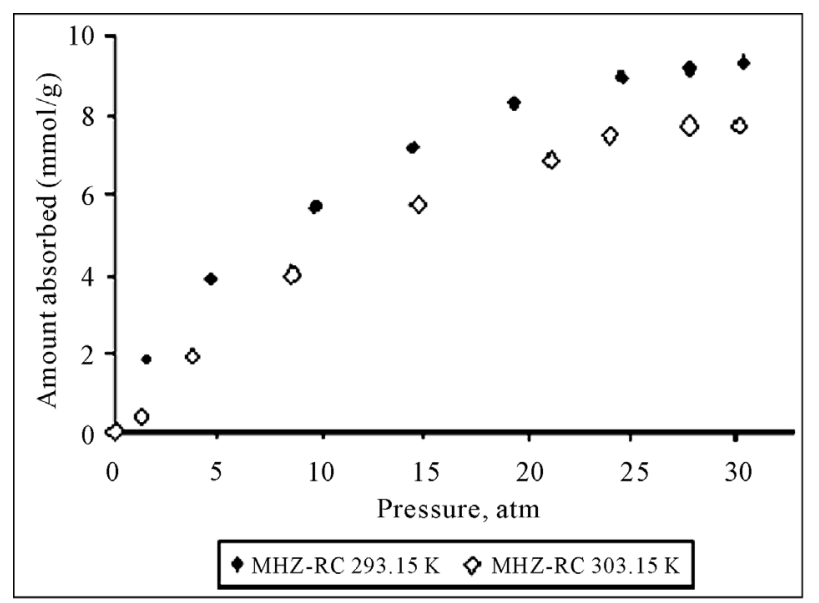

Figure 5. Methane adsorption capacity (by mass) of ACM1 at 298.15 $\mathrm{K}$ and $303.15 \mathrm{~K}$ and $30.00 \mathrm{~atm}$. cantly greater than the AC-RC starting material. In addition, because of their larger surface area, pore volume and total volume, monoliths obtained by chemical activetion and with PVA as a binder were able to adsorb 9.34 $\mathrm{mmol} / \mathrm{g}$ of methane. In contrast, the original activated carbon (AC-RC) obtained by physical activation only adsorbed $5.06 \mathrm{mmol} / \mathrm{g}$.

The adsorption capacity for methane was increased from $98 \mathrm{~V} / \mathrm{V}$ (AC-RC) to $130 \mathrm{~V} / \mathrm{V}$ (MHZ-RC). These results are novel for this type of material, and the high adsorption capacity for methane observed for the MHZ$\mathrm{RC}$ sample was found to be associated with its increased surface area and pore volume, which was developed via the synthesis route described. Our results show that provides greater storage capacity of methane using coffee husks. Other results using activated carbons synthesized from lignocellulosic residues such as waste olive oil have storage capacities of $59 \mathrm{~V} / \mathrm{V}$. Other authors have reported storage capacities between 64-94 V/V using coconut shells. Capacities up to $95 \mathrm{~V} / \mathrm{V}$ with acti- vated carbon from coconut shell activated with phospho- ric acid have also been reported. Other values for acti- vated carbon derived from waste tires have reached storage capacity of methane between $45-50 \mathrm{~V} / \mathrm{V}$.

\subsection{Isosteric Heats of Adsorption}

The variations in the isosteric heat of adsorption for the different adsorbate loadings were calculated using the Clapeyron equation. The isosteric heat of adsorption corresponds to the energy released during the adsorption process, and depends on the temperature and surface area. Figure 6 shows the isosteric heat of adsorption for methane for each of the different forms of activated carbon. Isosteric heats calculated from the experimental data varied with the different amounts of methane adsorbed.

The isosteric heat of adsorption is a valuable thermodynamic property, which provides useful information about the interactions between the adsorbent and the adsorbate, as well as the energetic heterogeneity of the adsorbent surface $[4,7,10,13,24]$. The isosteric heat of adsorption was determined based on the Clausius-Clapeyron equation $[5,52-56]$ :

$$
\frac{q_{s t}}{R T^{2}}=\left[\frac{\partial \ln P}{\partial T}\right]_{N}
$$

where $q_{s t}$ is the isosteric heat of adsorption, $\mathrm{R}$ is the gas constant, $\mathrm{T}$ is the temperature, $\mathrm{P}$ is the pressure and $\mathrm{N}$ is the adsorbed amount. In the present work, several isotherms at different temperatures were employed for determination of the dependence of the isosteric heat on the concentration of adsorbate. Figure 6 shows isosteric heats obtained in the present study for methane adsorption as a function of the amount of methane adsorbed. As 


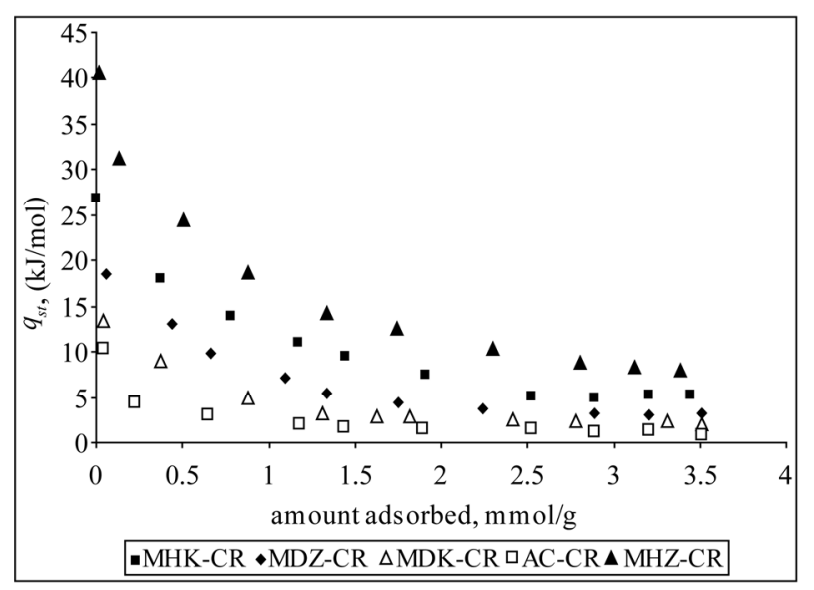

Figure 6. Isosteric heats of adsorption for methane for each of the different forms of activated carbon.

can be seen, the heat of adsorption decreases as the amount loading increases, consistent with the energetic heterogeneity of the carbon honeycomb monolith surfaces obtained under different synthesis conditions. During methane adsorption onto the different carbon monoliths, heats of adsorption varied with surface loading as follows: $40.00-8.00 \mathrm{~kJ} / \mathrm{mol}$ for MHZ-RC; 26.8 - 5.2 $\mathrm{kJ} / \mathrm{mol}$ for MHK-RC; 18.5-3.3 KJ/mol for MDZ-RC; $13.5-2.00 \mathrm{~kJ} / \mathrm{mol}$ for MDK-RC; and $[8,10,30] \mathrm{kJ} / \mathrm{mol}$ for AC-RC, $11.5-0.8 \mathrm{~kJ} / \mathrm{mol}$.

Overall, a mainly linear relationship was observed between methane adsorption capacities (by mass), adsorption affinities and isosteric heat adsorptions for the activated carbon honeycomb monoliths. For the MHZ-RC and MHK-RC monoliths, observed $q_{s t}$ values were lower than those reported in the literature [5]. This dif- ference may be due to textural characteristics of the monoliths synthesised in this study, because surface area, pore volume and pore width affect diffusion of methane to the interior pores of these samples, resulting in lower $q_{s t}$ values.

\section{Conclusions}

Activated carbon monoliths were synthesised from coffee husks and different materials, using PVA as a binder. The best methane storage capacity was observed for the MHZ-RC sample, which had the greatest surface area and total pore volume. Under the experimental conditions used in this work, methane storage capacity was a function of the total surface area and pore volume.

Measurement of isosteric heats demonstrated that the synthesised monoliths had heterogeneous surfaces from a thermodynamic point of view. Additionally, the obtained isosteric heats were consistent with the textural characteristics of the monoliths.

\section{Acknowledgments}

The authors thank the Departments of Chemistry of Universidad Nacional de Colombia, Universidad de Los Andes (Colombia) and the Master Agreement established between these institutions. Special gratitude is expressed to the Fondo Especial de Investigaciones de la Facultad de Ciencias de la Universidad de Los Andes (Colombia) for partial financing.

\section{REFERENCES}

[1] E. N. Rudisill, J. J. Jacskaylo and M. D. LeVan, "Coadsorption of Hydrocarbons and Water on BPL Activated Carbon," Industrial \& Engineering Chemistry Research, Vol. 31 No. 4, April 1992, pp. 1122-1130. doi: $10.1021 / \mathrm{ie} 00004 \mathrm{a} 022$

[2] R. N. Eissman and M. D. LeVan, "Coadsorption of Organic Compounds and Water Vapor on BPL Activated Carbon. 2. 1,1,2-Trichloro-1,2,2-Trifluoroethane and Dichloromethane," Industrial \& Engineering Chemistry Research, Vol. 32, No. 11, November 1993, pp. 2752- 2757. doi: $10.1021 / \mathrm{ie} 00023 \mathrm{a} 043$

[3] B. P. Russell and M. D. LeVan, "Coadsorption of Organic Compounds and Water Vapor on BPL Activated Carbon. 3. Ethane, Propane, and Mixing Rules," Industrial \& Engineering Chemistry Research, Vol. 36, No. 6, June 1997, pp. 2380-2389.doi:10.1021/ie960533+

[4] S. M. Taqvi, W. S. Appel and M. D. LeVan, "Coadsorption of Organic Compounds and Water Vapor on BPL Activated Carbon. 4. Methanol, Ethanol, Propanol, Butanol, and Modeling," Industrial \& Engineering Chemistry Research, Vol. 38, No. 1, December 1999, pp. 240-250. doi:10.1021/ie980324k

[5] L. Giraldo and J. C. Moreno-Piraján, "Synthesis of Activated Carbon Honeycomb Monoliths under Different Conditions for the Adsorption of Methane," Adsorption Science and Technology, Vol. 27, No. 3, November 2009, pp. 255-265. doi:10.1260/026361709789868901

[6] E. Costa, J. L. Sotelo, G. Calleja and C. Marron, “Adsorption of Binary and Ternary Hydrocarbon Gas Mixtures on Activated Carbon: Experimental Determination and Theoretical Prediction of the Ternary Equilibrium Data," American Institute of Chemical Engineers Journal, Vol. 27, No. 1, January 1981, pp. 5-12. doi:10.1021/la980492h

[7] I. L. Salame and T. J. Bandosz, "Experimental Study of Water Adsorption on Activated Carbons," Langmuir, Vol. 15, No. 2, December 1999, pp. 587-593.

[8] R. T. Yang, "Gas Separation by Adsorption Processes," Imperial College Press, London, 1997.

[9] D. G. Hartzog and S. Sircar, "Sensitivity of PSA Process Performance to Input Variables," American Institute of Chemical Engineers Annual Meeting, St. Louis, July 1993.

[10] M. S. Balathanigaimani, W. G. Shim, J. W. Lee and H. Moon, "Adsorption of Methane on Novel Corn Grain- 
Based Carbon Monoliths," Microporous and Mesoporous Materials, Vol. 119, No. 1-3, March 2009, pp. 47-52. doi:10.1016/j.micromeso.2008.09.034

[11] A. Perrin, A. Celzard, A. Albiniak, M. Jasienko-Halat, J. F. Marêché and G. Furdin, "NaOH Activation of Anthracites: Effect of Hydroxide Content on Pore Textures and Methane Storage Ability," Microporous and Meso-porous Materials, Vol. 81, No. 1-3, June 2005, pp. 31-40. doi:10.1016/j.micromeso.2005.01.015

[12] D. Lozano-Castello, J. Alcañiz-Monge, M. A. de la CasaLillo, D. Cazorla-Amoros and A. Linares-Solano, "Advances in the Study of Methane Storage in Porous Carbonaceous Materials," Fuel, Vol. 84, No. 1-4, September 2002, pp. 1777-1803. doi:10.1016/S0016-2361(02)00124-2

[13] V. C. Menon and S. Komarneni, "Porous Adsorbents for Vehicular Natural Gas. A Review," Journal of Porous Materials, Vol. 5, No.1, 1998, pp. 43-58. doi:10.1023/A:1009673830619

[14] R. Basumatary, P. Dutta, B. Prasad and K. Srinivasan, "Thermal Modeling of Activated Carbon Based Adsorptive Natural Gas Storage System," Carbon, Vol. 43, No. 3, January 2005, pp. 541-549. doi:10.1016/j.carbon.2004.10.016

[15] T. D. Burchell, "Carbon Materials for Advanced Technologies," Pergamon Press, Elmsford, 1999.

[16] D. F. Quinn and J. A. MacDonald, "Natural Gas Storage," Carbon, Vol. 30, No. 7, February 1992, pp. 1097-1103. doi:10.1016/0008-6223(92)90141-I

[17] J. Wegrzyn and M. Gurevich, "Adsorbent Storage of Natural Gas," Applied Energy, Vol. 55, No. 2, October 1996, pp. 71-83. doi:10.1016/S0306-2619(96)00015-3

[18] J. Sun, M. J. Rood, M. Rostam-Abadi and A. A. Lizzio, "Natural Gas Storage with Activated Carbon from a Bituminous Coal," Gas Separation \& Purification, Vol. 10, No. 2, June 1996, pp. 91-96. doi:10.1016/0950-4214(96)00009-6

[19] S. Sircar and D. V. Cão, "Heat of Adsorption," Chemical Engineering \& Technology, Vol. 25, No. 10, October 2002, pp. 945-948. doi:10.1002/1521-4125(20021008)25:10<945::AID-CEA T945>3.0.CO;2-F

[20] J. A. F. MacDonald and D. F. Quinn, "Carbon Absorbents for Natural Gas Storage," Fuel, Vol. 77, No. 1-2, January 1998, pp. 61-64. doi:10.1016/S0016-2361(97)00128-2

[21] J. W. Lee, H. C. Kang, W. G. Shim, C. Kim and H. Moon, "Methane Adsorption on Multi-Walled Carbon Nanotube at $(303.15,313.15$, and 323.15) K," Journal of Chemical \& Engineering Data, Vol. 51, No. 3, February 2006, pp. 963-967. doi:10.1021/je050467v

[22] M. S. Balathanigaimani, H. C. Kang, W. G. Shim, J. W. Lee, and H. Moon, "Preparation of Powdered Activated Carbon from Rice Husk and Its Methane Adsorption Properties," Korean Journal of Chemical Engineering, Vol. 23, No. 4 , March 2006, pp. 663-668. doi:10.1007/BF02706811
[23] J. W. Lee, M. S. Balathanigaimani, H. C. Kang, W. G. Shim, C. Kim and H. Moon, "Methane Storage on Phenol-Based Activated Carbons at $(293.15,303.15$, and 313.15) K," Journal of Chemical \& Engineering Data, Vol. 52, No. 1, January 2007, pp. 66-70. doi:10.1021/je060218m

[24] M. S. Balathanigaimani, M. J. Lee, W. G. Shim, J. W. Lee and H. Moon, "Charge and Discharge of Methane on Phenol-Based Carbon Monolith," Adsorption, Vol. 14, No. 4-5, May 2008, pp. 525-532. doi:10.1007/s10450-008-9131-z

[25] J. C. Moreno-Piraján and L. Giraldo, "Influence of Thermal Insulation of the Surroundings on the Response of the Output Electrical Signal in a Heat Conduction calorimetric Unit," Instrumentation Science \& Technology, Vol. 33, No. 4, July 2005, pp. 415-425.

[26] M. Huertemendia, L. Giraldo, D. Parra and J. C. MorenoPiraján, "Adsorption Microcalorimeter and Its Software: Design for the Establishment of Parameters Corresponding to Different Models of Adsorption Isotherms," Instrumentation Science \& Technology, Vol. 33, No. 6, November 2005, pp. 645-659.

[27] D. K. Steckler, R. N. Goldberg, Y. B. Tewari and T. J. Buckley, "High Precision Microcalorimetry: Apparatus, Procedures, and Biochemical Applications," Journal of the National Bureau of Standards, Vol. 91, 1986, pp. 113-121.

[28] R. S. Gunn, "Comparison Standards for Solution Calorimetry," The Journal of Physical Chemistry, Vol. 69, No. 9, September 1965, pp. 2902-2913. doi: $10.1021 / \mathrm{j} 100893 \mathrm{a} 015$

[29] D. J. Russell, D. Thomas and L. D. Hansen, "Batch Calorimetry with Solids, Liquids and Gases in Less than $1 \mathrm{~mL}$ Total Volume," Thermochimica Acta, Vol. 446, No. 1-2, July 2006, pp. 161-167. doi:10.1016/j.tca.2006.02.021

[30] J. Lerchner, G. Wolf, C. Auguet and V. Torra, "Accuracy in Integrated Circuit (IC) Calorimeters," Thermochimica Acta, Vol. 382, No. 1-2, January 2002, pp. 65-76. doi:10.1016/S0040-6031(01)00738-9

[31] M. S. Balathanigaimani, W. G. Shim, M. J. Lee, J. W. Lee, C. Kim and H. Moon, "Highly Porous Electrodes from Novel Corn Grains-Based Activated Carbons for Electrical Double Layer Capacitors," Electrochemistry Communications, Vol. 10, No. 6, June 2008, pp. 868-871. doi:10.1016/j.elecom.2008.04.003

[32] J. Lerchner, A. Wolf, G. Wolf and I. Fernandez, "Chip Calorimeters for the Investigation of Liquid Phase Reactions: Design Rules," Thermochimica Acta, Vol. 446, No. 1-2, July 2006, pp. 168-175. doi:10.1016/i.tca.2006.04.020

[33] E. Garrone, G. Ghiotti, E. Giamello and B. Fubini, "Entropy of adsorption by microcalorimetry. Part 1.-Quasiideal Chemisorption of CO onto Various Oxidic Systems," Journal of the Chemical Society, Faraday Transactions, Vol. 77, No.11, 1981, pp.2613-2620.

[34] L. Giraldo, J. I. Huertas, A. Valencia and J. C. Moreno- 
Piraján, "A Heat Conduction Microcalorimeter for Determination of the Immersion Heats of Activated Carbon into Aqueous Solutions," Instrumentation Science \& Technology, Vol. 31, No. 4, January 2003, pp. 385-397. doi:10.1081/CI-120025573

[35] O. Ioannidou and A. Zabanitou, "Agricultural Residues as Precursors for Activated Carbon Production-A Review," Renewable and Sustainable Energy Reviews, Vol. 11, No. 9, 2007, December 2007, pp. 1966-2005.

[36] K. Inomata, K. Kanazawa, Y. Urabe, H. Hosono and T. Araki, "Natural Gas Storage in Activated Carbon Pellets without a Binder," Carbon, Vol. 40, No. 1, January 2002, pp. 87-93. doi:10.1016/S0008-6223(01)00084-7

[37] M. S. Balathanigaimani, W. G. Shim, J. W. Lee, K. H. Park and H. Moon, "Effects of Structural and Surface Energetic Heterogeneity Properties of Novel Corn GrainBased Activated Carbons on Dye Adsorption," Microporous and Mesoporous Materials, Vol. 118, No. 1-3, February 2009, pp. 232-238. doi:10.1016/j.micromeso.2008.08.028

[38] D. Lozano-Castelló, D. Carzola-Amoros and A. LinaresSolano, "Usefulness of $\mathrm{CO}_{2}$ Adsorption at $273 \mathrm{~K}$ for the Characterization of Porous Carbons," Carbon, Vol. 42, No. 7, February 2004, pp. 1233-1242.

[39] D. C. S. Azevedo, J. C. S. Arújo, M. Bastos-Neto, A. E. B. Torres, E. F. Jaguarible and C. L. Cavalcante, "Microporous Activated Carbon Prepared from Coconut Shells Using Chemical Activation with Zinc Chloride," Microporous and Mesoporous Materials, Vol. 100, No. 1-3, March 2007, pp. 361-364. doi:10.1016/j.micromeso.2006.11.024

[40] M. J. Paruchner and F. Rodríguez-Reinoso, "Preparation of Granular Activated Carbons for Adsorption of Natural Gas," Microporous and Mesoporous Materials, Vol. 109, No. 1-3. March 2008, pp. 581-584. doi:10.1016/j.micromeso.2007.04.046

[41] H. J. Zhang, S. G. Chen and S. Guo, "Preparation of Natural Gas Adsorbents from High-Sulfur Petroleum Coke," Fuel, Vol. 87, No. 3, March 2008, pp. 304-311. doi:10.1016/j.fuel.2007.05.002

[42] M. Bastos-Neto, D. V. Canabrava, A. E. B. Torres, E. Rodriguez-Castellon, A. Jimenez-Lopez, D. C. S. Azevedo and C. L. Cavalcante, "Effects of Textural and Surface Characteristics of Microporous Activated Carbons on the Methane Adsorption Capacity at High Pressures," Applied Surface Science, Vol. 253, No. 13, April 2007, pp. 5721-5725. doi:10.1016/j.apsusc.2006.12.056

[43] A. Celzard and V. Fierro, "Preparing a Suitable Material Designed for Methane Storage: A Comprehensive Report," Energy Fuels, Vol. 19, February 2005, pp. 573-583. doi:10.1021/ef040045b

[44] A. Muto, T. Bhaskar, S. Tsuneishi and Y. Sakata, "Activated Carbon Monoliths from Phenol Resin and Carbonized Cotton Fiber for Methane Storage," Energy Fuels, Vol. 19, No. 1, January 2005, pp. 251-257. doi:10.1021/ef0400316

[45] L. Czepirski and J. JagieLLo, "Virial-Type Thermal Equa- tion of Gas-Solid Adsorption," Chemical Engineering Science, Vol. 44, No. 4, August 1989, pp. 797- 801. doi:10.1016/0009-2509(89)85253-4

[46] A. E. DeGance, "Multicomponent High-Pressure Adsorption Equilibria on Carbon Substrates: Theory and Data," Fluid Phase Equilibria, Vol. 78, October 1992, pp. 99137. doi:10.1016/0378-3812(92)87031-H

[47] J. C. Moreno-Piraján and L. Giraldo, "Setups for Simultaneous Measurement of Isotherms and Adsorption Heats," Review of Scientific Instruments, Vol. 76, No. 5, March 2005, pp. 1-8.

[48] S. Y. Zhang, O. Talu and D. T. Hayhurst, "High-Pressure Adsorption of Methane in $\mathrm{NaX}, \mathrm{MgX}, \mathrm{CaX}, \mathrm{SrX}$, and BaX," The Journal of Physical Chemistry, Vol. 95, No. 4, February 1991, pp. 1722-1726. doi:10.1021/j100157a044

[49] M. S. Sun, D. B. Shah, H. H. Xu and O. Talu, "Adsorption of Equilibria of C1-C4 Alkanes, $\mathrm{CO}_{2}$ and $\mathrm{SF}_{6}$ on Silicalite," The Journal of Physical Chemistry, Vol. 102, No. 1, January 1998, pp. 1466-1473.doi:10.1021/jp9730196

[50] J. H. Yun, D. K. Choi and S. H. Kim, "Adsorption of Organic Solvent Vapors on Hydrophobic Y-Type Zeolite," American Institute of Chemical Engineers Journal, Vol. 44, No. 6, June 1998, pp. 1344-1350.

[51] W. G. Shim, J. W. Lee and H. Moon, "Adsorption of Carbon Tetrachloride and Chloroform on Activated Carbon at (300.15, 310.15, 320.15 and 330.15) K," Journal of Chemical \& Engineering Data, Vol. 48, No. 2, January 2003, pp. 286-290. doi:10.1021/je020109h

[52] J. C. Moreno-Piraján, L. Giraldo, M. C. Baquero, N. Briceño and C. M. Díaz, "Influence of Temperature in the Processes of Carbonization and Activation with $\mathrm{CO}_{2}$ in the Obtainment of Activated Carbon from African Palm Pit. Study of the Modification of Characterization Parameters," Internet Journal of Chemistry, Vol. 6, 2003, pp. 6-21.

[53] R. Montero-Lago, A. Vallone and K. Sapag, "Natural Gas Storage in Microporous Carbon Obtained from Waste of the Olive Oil Production," Materials Research, Vol. 11, No. 4, December 2009, pp. 409-414.

[54] M. J. Prauchner and F. Rodriguez-Reinoso, "Preparation of Granular Activated Carbons for Adsorption of Natural gas," Microporous and Mesoporous Materials, Vol. 109, No. 1-3, April 2008, pp. 581-584. doi:10.1016/j.micromeso.2007.04.046

[55] R. B. Rios, F. W. M. Silva, A. E. B. Torres, D. C. S. Azevedo and C. L. Cavalcante, "Adsorption of Methane in Activated Carbons Obtained from Coconut Shells Using $\mathrm{H}_{3} \mathrm{PO}_{4}$ Chemical Activation," Adsorption, March 2009, Vol. 15, No. 3, pp. 271-277. doi:10.1007/s10450-009-9174-9

[56] T. A. Brady, T. A. M. Rostam-Abadi and M. J. Rood, "Applications for Activated Carbons from Waste Tires: Natural Gas Storage and Air Pollution Control," Gas Separation \& Purification, September 1996, Vol. 10, No. 2, pp. 97-102. doi:10.1016/0950-4214(96)00007-2 